\title{
Aspectos do coprocessamento de resíduos em fornos de clínquer
}

\author{
Aspects of waste co-processing in clinker kilns
}

\begin{abstract}
Sônia Denise Ferreira Rocha
Bacharel em Engenharia Química pela Universidade Federal de Minas Gerais (UFMG). Doutora em Engenharia Metalúrgica e de Minas pela UFMG. Professora da área de Processamento Mineral e Meio Ambiente da UFMG
\end{abstract}

Vanessa de Freitas Cunha Lins

Bacharel em Engenharia Química pela UFMG. Doutora em Engenharia Metalúrgica e de Minas pela UFMG.

Professora da área de Corrosão e Materiais da UFMG

Belinazir Costa do Espírito Santo

Graduado em Engenharia Química pela UFMG

\section{Resumo}

A prática do coprocessamento de resíduos na indústria de cimento tem se expandido devido à necessidade crescente de uma destinação ambiental e socialmente mais adequada de resíduos perigosos provenientes de diversos processos industriais. O objetivo deste trabalho foi realizar uma revisão sobre o coprocessamento de resíduos em fornos de clínquer, no Brasil e no mundo, visando contribuir para a otimização dos processos, identificando os aspectos já estudados e os que ainda demandam pesquisas. Foram abordados aspectos socioambientais e tecnológicos do coprocessamento, bem como a análise do ciclo de vida (ACV) na produção de cimento, e a produção técnico-científica sobre o coprocessamento.

Palavras-chave: coprocessamento; indústria de cimento; descarte de resíduos; combustíveis alternativos.

\section{Abstract}

The practice of co-processing of residues has increased due to the requirement of environmental and social friendly disposal of dangerous wastes from several industrial processes. The aim of this work was to perform a revision of co-processing of residues in Brazil and in the world, aiming at process optimization and also to identify the aspects already studied as well as those which still request research efforts. Social, environmental, and technological aspects of coprocessing were discussed in the present work as well as the life cycle analysis (LCA) in the cement production and the technical and scientific literature about co-processing.

Keywords: co-processing; cement industry; residue disposal; alternative fuels.

\section{Introdução}

A prática do coprocessamento de resíduos na indústria de cimento tem se expandido devido à necessidade crescente de uma destinação ambiental e socialmente mais adequada de resíduos provenientes de diversos processos industriais. Vários estudos vêm sendo conduzidos no sentido de se conhecer melhor os aspectos envolvidos nessa prática, já adotada em muitos países, inclusive no Brasil. Ainda existem diversos pontos a serem conhecidos e estudados, relacionados com essa atividade, que indubitavelmente demandam pesquisas. Esses trabalhos objetivam dar suporte a uma legislação adequada, a alterações e estabelecimento de procedimentos de processos, principalmente considerando a grande diversidade de resíduos que apresentam poder calorífico e de materiais inorgânicos que podem ter essa destinação. Uma oficina intitulada "A co-incineração de resíduos em fornos de cimento: uma visão da Justiça Ambiental sobre o chamado co-processamento" foi realizada em 2006 no Rio de Janeiro, por meio da cooperação do CESTEH/ENSP/FIOCRUZ com o GT Químicos, da Rede Brasileira de Justiça Ambiental (RBJA) e do Fórum Brasileiro de ONGs e movimentos sociais para o meio ambiente e o desenvolvimento (FBOMS). Os objetivos da oficina foram compartilhar informações técnicas, diagnósticos de problemas e experiências de intervenção frente ao problema da incineração e coincineração no Brasil, norteados por princípios de justiça ambiental. Nesse fórum, 
apresentaram-se argumentos e alguns estudos de caso a respeito dos efeitos da utilização de resíduos em fornos de clínquer para o meio ambiente e para a saúde de trabalhadores e das populações que vivem nas proximidades das indústrias cimenteiras. Durante a oficina, foi considerado como mais adequado para designar a prática adotada na indústria o termo coincineração em substituição ao termo coprocessamento. Quando o resíduo é utilizado como combustível, o termo adequado é coincineração; quando o resíduo é utilizado como fonte de calor e matéria-prima, podendo ser incorporado ao clínquer e melhorando a qualidade do produto, o termo mais apropriado é coprocessamento. Neste trabalho, o termo coprocessamento será usado quando o resíduo é utilizado apenas como combustível alternativo ou também como matéria-prima do processo, objetivando uma padronização.

Assim, o objetivo do presente trabalho foi realizar uma revisão sobre o coprocessamento de resíduos na indústria de cimento no Brasil e no mundo.

\section{Aspectos do coprocessamento de resíduos em fornos de clínquer}

O processo de fabricação de cimento é, essencialmente, a calcinação e a fusão de um material constituído aproximadamente de 94\% de calcário, 4\% de argilas e 2\% (p/p) de óxidos de ferro e alumínio em um forno rotativo operando em temperaturas de $1.450^{\circ} \mathrm{C}$ para os sólidos, em que a temperatura de chama oscila em torno de $2.000^{\circ} \mathrm{C}$. Nesse forno é produzido o clínquer. Devido, principalmente, às altas temperaturas no forno rotativo de clínquer, o complexo cimenteiro demanda o consumo de grandes volumes de combustíveis. Dessa forma, as cimenteiras são confrontadas com os dilemas da sustentabilidade, que vão desde a garantia de suprimentos de matéria-prima e de insumos energéticos até o cumprimento de normas e padrões.

Os dilemas da sustentabilidade no setor cimenteiro são evidenciados principalmente pelo aspecto econômico, o custo do suprimento de combustível. Assim, entre 1960 e 1970, essa indústria foi dependente do petróleo cru; depois migrou em parte para o carvão mineral e em parte para o carvão vegetal. Em 1990, introduziu-se o uso de resíduos renováveis e o uso dos resíduos industriais e sucatas no processo de produção de cimento. A utilização de resíduos industriais como combustível complementar aos convencionais e aos resíduos de origem vegetal colocou a indústria cimenteira em uma condição inédita, pois em vez de pagar por seu suprimento de combustíveis, ela passou a faturar com a recepção de resíduos para coprocessamento. Além dos aspectos econômicos, o coprocessamento contribui para compensar os problemas da alteração ambiental decorrente de toda a cadeia produtiva.

A concepção tecnológica do coprocessamento baseia-se na queima dos resíduos no forno rotativo de clínquer em condições especiais. Os resíduos são processados nos fornos rotativos devido às condições específicas do processo, como alta temperatura, ambiente alcalino, atmosfera oxidante, ótima mistura de gases e produtos, e tempo de residência (> 2 segundos) geralmente suficiente para a destruição de resíduos perigosos. Por outro lado, a utilização desses combustíveis alternativos no processo de produção de clínquer possui limitações como as relacionadas ao volume de combustível secundário que alimenta o forno, e limitações ligadas à segurança ambiental.

\section{Aspectos socioambientais do coprocessamento}

Durante a combustão dos resíduos, os materiais mais voláteis seguem rotas de emissão prejudiciais tanto às propriedades do cimento, como à saúde ocupacional e à saúde ambiental. Muitos desses resíduos, classificados como perigosos, contêm metais pesados, compostos organoclorados com cadeias vinílicas ou aromáticas, como as dioxinas e os furanos. De acordo com Milanez (2007), durante o coprocessamento desses resíduos, os metais pesados são redistribuídos, sendo os mais voláteis (tais como $\mathrm{Hg}$ e $\mathrm{Tl}$ ) emitidos juntamente com os gases pela chaminé principal do forno, os semivoláteis $(\mathrm{Cd}$, $\mathrm{Pb}, \mathrm{Sb}$, e $\mathrm{Se}$ ) e os não voláteis (As, $\mathrm{Cr}, \mathrm{Cu}, \mathrm{Ni}$ ) normalmente são incorporados ao clínquer. Devido, principalmente, a essas propriedades, os fornos de clínquer são considerados pela Agência de Proteção Ambiental dos Estados Unidos uma das maiores fontes de poluentes atmosféricos perigosos. Os níveis e as características das emissões dos poluentes atmosféricos dependem das características tecnológicas e operacionais do processo industrial, em especial, dos fornos rotativos de clínquer, da composição química e mineralógica dos insumos, e da composição química dos combustíveis. Nesse sentido, a queima de resíduos perigosos acarreta um passivo de emissões não desprezível com custos ambientais e sociais. Frente a esses riscos em potencial e aos parâmetros técnicos, Milanez (2007) argumenta que o processo do coprocessamento não destrói todos os poluentes presentes nos resíduos. Adicionalmente, a prática do coprocessamento pode aumentar significantemente a concentração desses materiais no cimento ou no pó do eletrofiltro, que normalmente é também incorporado à farinha crua.

Para mensurar o impacto da inalação desses materiais ricos em poluentes sobre a saúde das pessoas, Milanez (2007) cita os trabalhos de Winder e Carmody (2002) que estudaram as causas de dermatite em trabalhadores da construção civil, por contato com o caráter alcalino do cimento e por exposição crônica à ação irritante do cromo III e do cromo VI, comumente encontrados no cimento. Milanez (2007) cita ainda outros trabalhos que indicaram uma forte relação entre a exposição crônica a dioxinas e furanos e o aumento de incidência de câncer, problemas reprodutivos, deficiência imunológica e problemas do sistema endócrino. Nos seus estudos de saúde ocupacional e ambiental na produção do cimento e no coprocessamento praticado em países em desenvolvimento, o autor verificou que, nesses países, os funcionários trabalham sem equipamentos de proteção individual e 
em ambientes inadequados. Em outros casos, apesar de os empregados receberem tais equipamentos, eles não são usados adequadamente. Dentro desse contexto, surgem situações de grande exposição a fatores de risco, que se tornam problemas de saúde. Em termos de saúde ambiental, esse autor verificou que, assim como nos casos de saúde dos trabalhadores, a fabricação do cimento e o coprocessamento geram impactos negativos sobre a qualidade do ar respirado pela população no entorno da planta.

Porto e Fernandes (2006) discutiram os riscos ambientais e ocupacionais associados à queima de resíduos em fornos de clínquer. Os autores sugerem a necessidade da integração do conhecimento com a participação de autoridades e empregados das indústrias para a redução das vulnerabilidades inerentes ao coprocessamento.

Carpio (2005) apresenta um modelo de otimização para o uso de resíduos industriais como combustíveis alternativos considerando-se restrições de qualidade, consumo específico de calor, emissão de poluentes, dentre outros fatores. Na modelagem, foram utilizadas duas técnicas de otimização: a determinística, o método de programação sequencial quadrática, em combinação com o método de Monte Carlo, e a heurística, por meio do algoritmo genético e evolução diferencial. Foram calculados os níveis de substituição do combustível primário pelo alternativo derivado dos resíduos industriais, levandose em conta os limites aceitáveis de emissão de poluentes.

\section{Aspectos tecnológicos do coprocessamento}

Os combustíveis alternativos tradicionalmente usados na indústria cimenteira, tais como bagaço de cana, casca de arroz, casca de coco, resíduos de madeira, lenha, moinha de carvão vegetal, pneus, alcatrão, coque de petróleo, moinha de coque, turfa, rejeitos carbonosos e gás proveniente do processo de pirólise são derivados de resíduos sólidos, líquidos, municipais e industriais. Além desses, Mokrizycki e Uliasz-Bochenczyk (2003) identificaram ainda combustíveis especiais, alternativos e híbridos, derivados de misturas de resíduos, desenvolvidos na Europa Ocidental e na Polônia.

Uma das matérias-primas utilizadas no coprocessamento é a moinha de carvão adicionada na fase de preparo do resíduo também conhecida como blendagem. A finalidade desse carreador é retirar a umidade dos resíduos e dar fluidez ao material quando adicionado ao forno de clínquer. A geração dessa moinha e sua respectiva disponibilidade no mercado vêm reduzindo-a drasticamente. Dentro desse contexto, Lins et al (2007) estudaram possíveis materiais como o carvão, caulim, anfibolito, quartzo, raspa de pneu, fuligem de caldeira, pó de poli (tereftalato de etileno), PET, escória moída, resíduos de outros processos industriais, que, em conjunto ou isoladamente, pudessem substituir a moinha no processo de coprocessamento. Lins et al (2007) concluíram que o anfibolito, o caulim, a fuligem de caldeira e o carvão são resíduos que podem substituir a moinha. Já nas unidades de produção de cimento onde os resíduos coprocessados são usados como combustíveis, nenhum dos resíduos estudados possui características adequadas para a utilização como combustível. Apenas o pó de poli (tereftalato de etileno), PET, possui poder calorífico inferior (PCI) superior ao mínimo permitido; porém, por conter baixo teor de sólidos, sua utilização não é viável.

De acordo com os estudos de Santi e Sevá Filho (1999), muitos dos principais tipos de resíduos empregados no coprocessamento têm relação direta com os disponíveis nas regiões onde as fábricas estão instaladas, reduzindo, dessa forma, os gastos com frete. A legislação brasileira (Resolução 264 Conselho Nacional de Meio Ambiente - CONAMA, 1999) estabelece duas classes de resíduos que podem ser coprocessados em processos industriais: os resíduos que podem substituir, em parte, a matéria-prima, caso tenham características similares a esta; e os resíduos com alto poder energético que podem ser usados como combustíveis secundários. Geralmente, ambos os tipos de resíduos são tratados em fornos rotativos de clínquer, devido às características do processo, tais como o longo tempo de residência e as altas temperaturas alcançadas que garantem a destruição dos resíduos e permitem que alguns metais pesados se incorporem à estrutura do clínquer.

Ract, Espinoza e Tenorio (2003) estudaram a possibilidade de coprocessar lodos galvânicos, contendo os metais pesados $\mathrm{Cu}$ e Ni, em fornos de clínquer. Vale ressaltar que lodos galvânicos são classificados como resíduos perigosos pela Associação Brasileira de Normas Técnicas (ABNT), desde 1987. Em suas análises químicas da matériaprima e do lodo galvânico, os pesquisadores verificaram que o teor de $\mathrm{Cu}$ e Ni aumentaram de 2 ppm e 58 ppm para 2,4 e 1,2\% (p/p) respectivamente com a introdução dos lodos galvânicos em relação à matéria prima do clínquer. A partir desses resultados, Ract, Espinoza e Tenorio (2003) realizaram testes de queima da matéria prima do clínquer e misturas contendo 0,$25 ; 0,5 ; 1,0 ; 2,0 ; 3,0$ e 5\% (p/p) de lodos galvânicos. Os resultados dessa análise indicaram que quanto maior a concentração de lodos galvânicos, maior a tendência de redução de temperatura quando acontece a reação de $C_{2} S$ e a formação de líquido. Por outro lado, os autores observaram que concentrações de lodos galvânicos acima de 2\% (p/p) não afetaram as reações de clinquerização. Ract, Espinoza e Tenorio (2003) observaram ainda que $100 \%$ (p/p) do Ni e 99\% (p/p) do Cu incorporaram-se na matriz do clínquer durante o processo de queima.

Mirolli (2005) propõe utilizar a energia calorífica resultante do uso de resíduos do processo de produção do cimento para gerar energia elétrica sem nenhum consumo adicional de combustíveis. Para isso, o autor apresenta o denominado Ciclo Kalina ${ }^{\circledR}$, um processo de conversão de energia que utiliza a mistura amônia e água em um ciclo planejado para maximizar a produção de eletricidade de uma fonte de calor dos resíduos, sem interferir no processo de produção de cimento. Além de reduzir o custo da energia elétrica na produção de cimento, o coprocessamento pelo Ciclo Kalina ${ }^{\circledR}$ oferece a oportunidade de adquirir benefícios adicionais, como créditos de carbono, 
por meio de implementação de projetos de cogeração que diminuirá as emissões de $\mathrm{CO}_{2}$ da queima de combustíveis fósseis nos fornos de clínquer.

Outro tema importante abordado na literatura é o co-processamento de pesticidas (KARSTENSEN et al, 2006). O acúmulo e a gerência inadequada de pesticidas obsoletos e outros produtos químicos perigosos constituem uma ameaça para a saúde pública e para o meio ambiente, e os fornos de clínquer apresentam-se em condições ótimas para tratamento desses resíduos perigosos. Como já citado, o processo apresenta temperaturas elevadas $\left(1.450-2.000^{\circ} \mathrm{C}\right)$, longo tempo de residência, excesso de oxigênio durante e depois da combustão, boas condições de turbulência e de mistura, inércia térmica, incorporação de metais pesados ao clínquer; não há produção de compostos indesejados como a escória, os resíduos líquidos e as cinzas são aproveitados como parte da matéria-prima, e a energia é recuperada para o sistema. Entretanto, o coprocessamento desses resíduos requer um apurado sistema de monitoramento e controle de efluentes atmosféricos no processo de produção de cimento. Karstensen et al (2006) revelam que testes realizados em países desenvolvidos têm demonstrado que não existe necessariamente uma correlação nas emissões ambientais ou na qualidade do produto com a utilização de resíduos como fonte substitutiva de combustíveis e matérias primas no forno de cimento. A surpresa nos estudos do autor é que as melhores técnicas de coprocessamento são aplicadas quando novas plantas são construídas em mercados emergentes e em países em desenvolvimento. Nesse sentido, Karstensen et al (2006) investigaram a forma como pesticidas obsoletos e poluentes orgânicos são destruídos em fornos de cimento de países em desenvolvimento. Assim, os autores descreveram como diferentes processos foram realizados na Malásia, no Paquistão, na Tanzânia, na Polônia, e em que condições foi realizado o projeto de queima de resíduos no sul do Vietnã. Os autores concluíram que, embora nenhum dos projetos estudados tenha demonstrado eficiência plena na destruição dos resíduos, esse tratamento tem conseguido importante aceitação dentre as apostas industriais para o destino dos resíduos.

O teste de queima de uma cimenteira no Vietnã foi conduzido em uma planta que produz, aproximadamente, 4.400 ton/dia de clínquer. O solvente tinha como base uma mistura de dois inseticidas, $18,8 \%$ de Fenobucard $\left(\mathrm{Cl}_{2} \mathrm{H}_{17} \mathrm{NO}_{2}\right)$ e $2,4 \%$ de Fipronil $\left(\mathrm{Cl}_{2} \mathrm{H}_{4} \mathrm{Cl}_{2} \mathrm{~F}_{6} \mathrm{~N}_{4} \mathrm{OS}\right)$. Tanto o Fenobucard como o Fipronil são inseticidas ativos e classificados como relativamente perigosos (Classe II) pela Organização Mundial da Saúde. Os resultados desses testes demonstraram uma eficiência de destruição 100 mil vezes melhor do que a requerida pela legislação dos Estados Unidos, exceto para as emissões de $\mathrm{NO}_{\mathrm{x}}$. Segundo Karstensen et al (2006), todas as medições de poluentes orgânicos se mostraram abaixo dos limites de detecção das leis ambientais internacionais. Isso prova que a destruição foi completa e irreversível e de acordo com a Convenção de Estocolmo para a poluição atmosférica. Os autores enfatizaram que o forno de clínquer pode se tornar uma alternativa viável e sustentável para tratar diversos produtos químicos perigosos e combater a poluição atmosférica, desde que procedimentos adequados de monitoramento e controle sejam adotados.

Dentre as várias indústrias, a siderúrgica gera um nível elevado de resíduos perigosos ao meio ambiente e ao ecossistema, uma vez que esses resíduos contêm grande quantidade de metais pesados instáveis. Com o objetivo de imobilizar esses metais, Malviya e Chaudhary (2006) desenvolveram um processo (método "S/S") capaz de converter os metais para uma forma menos instável. Dessa forma, os autores identificaram o cimento Portland como um suporte ideal para viabilizar esse método, por possuir $\mathrm{pH}$ alto o suficiente para imobilizar vários metais tóxicos, por reação de precipitação, absorção e adsorção. Utilizando-se de testes de lixiviação, Malviya e Chaudhary (2006) avaliaram a efetividade da imobilização. Com os limites da mobilidade e mecanismo de lixiviação baseados na Equação 1, Malviya e Chaudhary (2006) concluíram que o cimento foi efetivo para imobilizar os metais pesados ( $\mathrm{Pb}, \mathrm{Zn}, \mathrm{Fe}, \mathrm{Cu}$ e Mn) presentes nos resíduos do processo de produção de aço. Outra observação desses pesquisadores é de que o pH e a solubilidade dos hidróxidos de metais controlam o processo quando se aumenta a dosagem de resíduo na matriz. Destes princípios, os autores verificaram que a difusão não é o mecanismo controlador da lixiviação para os metais analisados.

$\sum \frac{a_{n}}{A_{0}} \frac{V}{S}=2 \frac{D_{e}^{1 / 2}}{\pi} t_{n}^{1 / 2}$ Equação 1

Onde:

$a_{n}$ : quantidade de contaminante liberada durante o período (mg);

$A_{0}$ : quantidade inicial de contaminante na amostra (mg);

$V$ : volume da amostra $\left(\mathrm{m}^{3}\right)$;

$S$ : a área superficial da amostra $\left(\mathrm{m}^{2}\right)$,

$t_{n}:$ tempo (s);

$D_{e}$ : coeficiente de difusão efetiva $\left(\mathrm{m}^{2} / \mathrm{s}\right)$.

Ainda na linha do coprocessamento de resíduos da indústria siderúrgica, está o trabalho de Caponero e Tenório (1999) que utilizaram lama fosfática, resíduo do tratamento superficial de metais, o qual contém basicamente água, ferro e fosfato de zinco, além de alguns outros elementos como $\mathrm{Na}, \mathrm{S}, \mathrm{K}, \mathrm{Pb}, \mathrm{Cr}$ e $\mathrm{Cu}$, em menores quantidades. As condições presentes em fornos rotativos sugerem que esses elementos estarão presentes na forma de óxidos, durante o processo de clinquerização. Uma contribuição particular desses óxidos na matéria prima é a de que o óxido de zinco facilita a formação de várias fases do clínquer. Como o clínquer bruto normalmente não apresenta quantidades significativas de $\mathrm{ZnO}$, a proposta é aumentar a quantidade dessa substância para reduzir a temperatura de clinquerização e diminuir o consumo de combustíveis. Adições de 1-3\% (p/p) de ZnO podem representar uma diminuição de $50-100^{\circ} \mathrm{C}$ e cerca de $86-90 \%$ $(\mathrm{p} / \mathrm{p})$ do zinco introduzido é incorporado à matriz do clínquer. 
Os estudos de Genon e Brizio (2008) concentram atenção particular na destruição dos resíduos derivados de combustíveis em fornos de cimento. Em 2005, um grupo cimenteiro foi autorizado a usar 15 mil ton/ano de refuse derived fuel (RDF) e 60 mil ton/ano de refeição animal juntamente com 130 mil ton/ano de combustíveis fósseis nas plantas de Lombardia, Itália. A substituição dos combustíveis convencionais por esses combustíveis secundários pôde ser avaliada, sob o ponto de vista tecnológico, começando por considerar os balanços de massa e de energia dos substituintes. Assim, a utilização dos RDF como combustível substituinte, embora com menor poder calorífico, tanto pode conduzir a mesma condição térmica como manter o mesmo fator de diluição, diminuindo a taxa de emissão de $\mathrm{NO}_{\mathrm{x}}$. Geralmente, encontram-se nos combustíveis substituintes maiores concentrações de nitrogênio, sulfeto e cloreto, em relação aos combustíveis fósseis. $\mathrm{O}$ nitrogênio é responsável pela formação de $\mathrm{NO}_{\mathrm{x}}$, considerado um perigoso poluente atmosférico. Ao contrário destes, devido ao caráter alcalino da matriz do clínquer, a presença de sulfetos e cloretos nos combustíveis substituintes não causa níveis críticos de emissões gasosas. A incorporação de cloretos no clínquer é danosa, uma vez que o cloreto destrói a camada passiva das armaduras de aço em concreto armado e sua presença no cimento deve ser evitada. Contudo, os relatórios publicados pela Comissão Europeia em 2003, esclarecem a contribuição positiva da utilização de RDF em fornos de clínquer em termos de redução nas emissões de $\mathrm{CO}_{2}$ em relação a combustíveis convencionais como o carvão. O impacto negativo dessa prática reside na transferência de metais pesados ( $\mathrm{Sb}, \mathrm{Hg}, \mathrm{Cd}$, As, $\mathrm{Cu}, \mathrm{Cr}$, $\mathrm{Tl}$ e $\mathrm{Zn}$ ) para a atmosfera ou para o clínquer produzido. Genon e Brizio (2008) ressaltaram que o uso de combustíveis alternativos pode piorar as emissões de metais pesados, apresentando-se perigosamente fora dos limites estabelecidos pelos órgãos ambientais. Após abordar as principais vantagens e desvantagens da prática de coprocessamento de RDF em fornos de clínquer, Genon e Brizio (2008) ressaltaram o baixo custo do resíduo no mercado italiano e a grande contribuição da indústria cimenteira para a redução das emissões de dióxido de carbono.

Zabaniotou e Theofilou (2008) utilizaram uma mistura de lamas de esgoto provenientes do tratamento de água e coque de petróleo como combustíveis alternativos na queima do clínquer na produção de cimento Portland no Chipre. Os autores visaram diminuir a dependência de combustíveis não renováveis e reduzir a emissão de poluentes durante a queima. Os estudos mostraram que, ao se utilizar lamas de esgoto secas como combustível alternativo necessita-se de cerca de $2 \%$ (p/p) menos ar de combustão do que quando se usa somente coque de petróleo como combustível. Segundo os autores a vantagem de se usar lamas como combustível alternativo é que, ao se utilizar 7,5\% (p/p) de lama em um forno que normalmente seria alimentado com 6,3 ton/hora de coque de petróleo, a economia é de cerca de 8,00 euros/hora. Além disso, a alta volatilidade das lamas provoca uma melhor queima do coque de petróleo e diminui a produção de resíduos em forma de cinza no produto final dos fornos de clínquer. As cinzas produzidas são similares àquelas produzidas sem a presença de lamas de esgoto nos fornos. Adicionalmente, outra vantagem de se coprocessar lamas é o rápido resfriamento desse combustível proporcionando uma redução na emissão de dioxinas e furanos. As emissões de dioxinas e furanos para a atmosfera ocorrem principalmente nos processos de combustão. Esses compostos são detectados em todas as matrizes ambientais: água, ar, solo, sedimentos, água, animais e vegetais. Dioxinas e furanos se acumulam nos tecidos gordurosos, especialmente nos alimentos de origem animal (ASSUNÇÃO E PESQUERO, 1999; DICKSON E KARASEK, 1987; MILLIGAN E ALTWICKER, 1993). Não se sabe ao certo se dioxinas e furanos já estão presentes nos resíduos, se são produzidas devido à presença de precursores (como a bifenila policlorada e os benzenos clorados), ou se são formadas a partir de compostos não diretamente considerados perigosos como hidrocarbonetos clorados, íons de cloreto inorgânico ou plásticos (ASSUNÇÃO e PESQUERO, 1999). Embora as temperaturas dos fornos de cimento sejam suficientes para destruir as dioxinas e furanos, existe a possibilidade de esses compostos se formarem novamente no processo de resfriamento dos gases (SWEETMAN et al, 2004). Dessa forma, os fornos de cimento são considerados pela Agência de Proteção Ambiental dos Estados Unidos uma das maiores fontes de poluentes atmosféricos perigosos, incluindo dioxinas e furanos (SIDHU et al, 2001). Também, por ser um combustível de biomassa, a lama de esgoto propicia uma redução da emissão de $\mathrm{CO}_{2}$ para a atmosfera. Foi observado que o ambiente alcalino do forno ajuda a remover traços de ácidos como $\mathrm{HCl} e$ HF produzidos durante a queima e que a utilização de lama como combustível alternativo reduz a necessidade do uso de combustíveis convencionais, não renováveis.

Um problema avaliado foi a emissão de mercúrio em gases combustíveis, parâmetro muito fiscalizado pela União Europeia. Normalmente, o mercúrio é proveniente do tratamento de metais, incineração de resíduos, queima de combustíveis fósseis, entre outros. A presença de mercúrio nas lamas estudadas por Zabaniotou e Theofilou (2008) foi proveniente do processo de uma planta de tratamento de esgotos. Na planta de cimento estudada por Zabaniotou e Theofilou (2008), as emissões de metais pesados representaram apenas 16\% (p/p) em relação aos níveis aceitos, já as emissões de dioxinas e furanos apenas $6 \%$ em relação aos níveis aceitáveis. Assim, esses autores concluíram que o coprocessamento de lamas de esgoto como combustível alternativo em fornos de cimento é satisfatório. A prática ajuda a economizar energia durante a queima do combustível, além do apelo ambiental, possibilitando uma destinação correta a um resíduo que poderia provocar danos ao meio ambiente se fosse descartado de forma irregular.

Tosta et al (2007) realizaram um trabalho de revisão acerca da produção mundial de cimento, dos processos adotados, dos combustíveis utilizados e de como a utilização de resíduos atua nessa 
produção. Observaram um grande destaque para o papel da China e da Índia na produção de cimento, que juntas representam cerca de $50 \%$ da produção mundial, valor justificado pelo crescimento dessas duas economias nos últimos anos. Vale ainda ressaltar que o Brasil aparece entre os 15 maiores produtores mundiais de cimento. Segundo os autores, o coprocessamento de resíduos é cada vez mais utilizado, uma vez que essa prática atende a dois aspectos bem atuais, que são o apelo energético e o ambiental.

Puertas et al (2008) avaliaram a reatividade e a queima do cimento Portland quando a matéria prima foi parcialmente substituída por resíduos cerâmicos. Três combinações de cerâmica branca e cerâmica vermelha foram testadas. O trabalho mostrou que a composição química e mineralógica de alguns tipos de cerâmicas utilizadas foi apropriada para serem misturadas às matérias-primas na produção de cimento. Os resíduos estudados foram gerados em plantas de produção de telhas e tijolos de cerâmica. A reatividade da mistura depende de sua composição química, da natureza mineralógica do resíduo cerâmico e do tamanho das partículas. Os autores observaram maior reatividade da mistura em comparação com a matéria-prima convencional quando partículas menores que $90 \mu \mathrm{m}$ foram utilizadas. Já para partículas maiores do que $90 \mu \mathrm{m}$, a reatividade foi notoriamente menor. Além disso, o clínquer obtido a partir dessas misturas apresentou maior quantidade de cal livre em todas as combinações testadas. Misturas com resíduos apresentando menor tamanho de partículas apresentaram maior capacidade de queima do que as misturas convencionais.

Abordando a questão de sustentabilidade tecnológica do coprocessamento, Winingham (1993) discutiu a segurança da utilização de resíduos industriais como combustíveis alternativos em fornos de cimento. De acordo com as suas observações, Winingham (1993) concluiu que a atividade de coprocessamento de resíduos em fornos de cimento pode ser praticada, de forma segura, em condições em que se tenha adequada instrumentação para as medições necessárias de variáveis de processo selecionadas visando a um monitoramento eficiente.

\section{Análise de ciclo de vida na produção de cimento}

A análise do ciclo de vida (ACV) é uma metodologia utilizada para avaliar a carga poluidora e os impactos ambientais associados a um produto, processo, ou atividade, por meio dos fluxos de energia e materiais usados e das emissões para o meio ambiente. A avaliação inclui o ciclo de vida inteiro do produto, do processo ou da atividade, abrangendo a extração e o processamento de matérias primas, o transporte, a distribuição, a utilização, a manutenção, a reutilização, a reciclagem e a disposição final (Hunkeler et al, 2008). A avaliação dos impactos do ciclo de vida (LCIA) é uma das etapas básicas da metodologia de ACV (SETAC, 1993). Recentemente, vários estudos utilizando a metodologia ACV vêm sendo desenvolvidos no contexto da produção de cimento (HUNTZINGER E EATMON, 2008; JOSA et al, 2007; NAVIA et al, 2006; LEE E PARK, 2004). Huntzinger e Eatmon (2008) utilizaram a ACV para avaliar os impactos ambientais de quatro diferentes configurações de processo: (1) o processo convencional de produção de cimento; (2) cimento blendado (pozolanas naturais); (3) cimento em que 100\% do pó residual do forno foi reciclado e inserido novamente ao processo e (4) cimento Portland produzido quando o material particulado do forno foi usado para sequestrar uma porção do $\mathrm{CO}_{2}$ emitido. Navia et al (2006) avaliaram a utilização de solo vulcânico previamente usado na remoção de metais de efluentes industriais no coprocessamento e compararam essa alternativa com o processo convencional, sem coprocessamento. O estudo de Josa et al (2007) apresenta uma análise comparativa de diferentes estudos de ACV para diferentes inventários na produção de cimento na Europa. Categorias de impactos consideraram o processo e impactos tais como efeito estufa, acidificação, eutrofização e smog de verão e inverno. Já o trabalho de Lee e Park (2004) objetivou quantificar o crédito ambiental advindo da utilização de escória de alto forno granulada na produção de cimento.

Os estudos e pesquisas empregando a ACV possibilitam uma análise global do coprocessamento e a quantificação dos impactos associados ao processo, focando desde a utilização de recursos naturais até o final da vida útil dos produtos do cimento. Entretanto, os resultados não podem ser extrapolados de uma área para outra, e cada resíduo coprocessado deve ser objeto de estudo, uma vez que suas características físicas e químicas podem alterar os resultados. Esse é um campo de estudo bastante amplo e de potencial importância.

\section{Coprocessamento de resíduos em fornos de cimento no Brasil}

O coprocessamento surgiu como uma estratégia para melhorar o desempenho econômico (menor consumo energético) da indústria cimenteira. Em resposta à crise desencadeada pela recessão da economia brasileira nos finais da década de 1980, o setor cimenteiro implementou estratégias para conciliar o custo da automação e a redução de pessoal. Nesse contexto, o coprocessamento de resíduos iniciou-se no início da década de 1990 nas cimenteiras de Cantagalo do Estado do Rio de Janeiro. Desde então, essa tecnologia é usada, mas sob a legislação de agências de controle ambiental e autoridades da saúde. No entanto, devido à carência de profissionais treinados nesse setor, em 1995, vários jornais brasileiros já advertiam sobre o desconhecimento da relação de causa e efeito entre a exposição de operários aos produtos químicos e os danos em sua saúde. Dessa forma, os jornais publicaram artigos denunciando suspeitas de intoxicação e alergias de pele em trabalhadores das indústrias cimenteiras de Cantagalo. Estudiosos correlacionaram esses problemas a várias situações de risco como exposição a 
emissões de dioxinas e de metais pesados. Há todo um sistema de órgãos federais destinado a atribuir eficácia à legislação ambiental. O Sistema Nacional do Meio Ambiente (SISNAMA) compreende o Conselho Nacional do Meio Ambiente (CONAMA, órgão normativo, consultivo e deliberativo), o Ministério do Meio Ambiente (órgão central com atribuições de coordenação, supervisão e controle da Política Nacional de Meio Ambiente), e o Instituto Brasileiro de Meio Ambiente e dos Recursos Naturais Renováveis (IBAMA, o órgão executivo). Completam o SISNAMA, ainda, outros órgãos da administração federal, fundações públicas voltadas à proteção do meio ambiente, e entidades dos poderes executivos estaduais e municipais (Secretarias Estaduais e Municipais do Meio Ambiente; Agências Ambientais - CETESB/FEEMA/COPAM/IAP/CRA e outras), em suas respectivas jurisdições. Em termos legais, as principais normas federais para controle de emissões dos fornos de cimento são a Resolução CONAMA 264/1999, que dispõe sobre procedimentos e os critérios específicos da coincineração, e a Resolução CONAMA $316 / 2002$, que trata dos procedimentos e dos critérios para o funcionamento de sistemas de tratamento de resíduos. Nos Estados, existem normas rigorosas e específicas acerca da disposição de resíduos. A Companhia de Tecnologia de Saneamento Ambiental de São Paulo, por exemplo, publicou uma Norma Técnica, em dezembro de 2003, intitulada "Procedimento para utilização de resíduos em fornos de produção de clínquer".

Existem, entretanto, falhas associadas ao texto da legislação, bem como sua fiscalização e controle. Milanez (2007) descreve as fragilidades legais na regulação do coprocessamento e as falhas na fiscalização e na concessão de licenças, devido a limitações institucionais das agências ambientais.

Porto e Fernandes (2006) estudaram quais os pontos vulneráveis do controle e fiscalização do processo e até que ponto a população, no entorno das plantas cimenteiras, estaria vulnerável aos efeitos dessa prática. O trabalho de Porto e Fernandes (2006) alerta para a possibilidade de contaminações de cimentos nacionais ou importados, provenientes das rotas de fabricação, muitas vezes desconhecidas, onde os combustíveis alternativos, como os pneus inservíveis, podem ser fontes permanentes não declaradas de contaminações ambientais e do próprio cimento produzido. O caso específico de coprocessamento de pneus inservíveis é praticado no Brasil há mais de uma década. A alternativa de se queimar pneus advém do seu alto poder calorífico, representando uma grande economia de energia associada à possibilidade de uma destinação para enormes volumes de passivo ambiental. Um dos grandes problemas do coprocessamento de pneus se deve à presença do enxofre na estrutura da borracha. Quando o enxofre utilizado na vulcanização da borracha é proveniente de minérios sulfetados, pode ainda ocorrer a contaminação por arsênio, que se volatilizaria na temperatura do forno, causando sérios problemas ambientais (SANTI, 2003; MOORE, 1995; MAINIER; ROCHA, 2003). O sulfeto arsenioso
$\left(\mathrm{As}_{2} \mathrm{~S}_{3}\right)$ associado ao minério de zinco pode reagir, formando o arsênio e incorporando-se ao enxofre produzido. A contaminação é aleatória, pois depende do teor de arsênio existente no minério. Por outro lado, é pouco provável a contaminação com arsênio quando o enxofre é obtido partir de depósitos geológicos ou quando é produzido a partir de sulfeto de hidrogênio (H2S) existente no gás natural. Por motivos técnicos, o enxofre contaminado com arsênio não pode ser empregado na fabricação de ácido sulfúrico, fertilizantes e outros compostos químicos de indústria de base, entretanto, na vulcanização de borracha para pneus não foi encontrada nenhuma restrição ao seu uso. Porém, quando se vislumbra o coprocessamento de pneus, a restrição quanto à origem do enxofre deve ser praticada. Segundo Monteiro e Mainier (2008), a queima total de uma tonelada de pneus pode significar uma emissão teórica de 2,56 ton de $\mathrm{CO}_{2}$ e $26 \mathrm{~kg}$ de $\mathrm{SO}_{2}$ para a atmosfera. Considerando ainda que o enxofre contido em uma tonelada de pneu tenha, respectivamente, 0,1, 0,5 e 1\% de arsênio, a emissão para a atmosfera de óxido arsenioso seria de 17, 85 e 170 g, respectivamente. Esses valores parecem desprezíveis, porém tornam-se extremamente significativos uma vez acumulados no ambiente.

Outro risco, não menos irrelevante, de se utilizar pneus como resíduos a serem coprocessados é desencadeado quando se eleva a importação de pneus usados como resíduo ou para serem reformados, o que aumenta a quantidade de resíduos no país. Uma vez identificados os pontos de vulnerabilidade populacional e institucional, Porto e Fernandes (2006) apresentaram algumas estratégias para reduzir os riscos de gerenciamento e estabelecer normas para a queima de resíduos em fornos de clínquer. Eles concluíram que o trabalho integrado de instituições ambientais, agências de saúde e autoridades jurídicas seria a chave estratégica para promover a segurança e a saúde dos trabalhadores da indústria de cimento. Segundo os estudos que Porto e Fernandes (2006) realizaram em cimenteiras instaladas no Brasil, as estratégias de integração de metodologias para reduzir as vulnerabilidades sociais e promover a segurança do coprocessamento no Brasil podem e devem ser válidas não somente para países em industrialização na América Latina, África ou Ásia como também para países mais ricos e desenvolvidos.

Segundo o relatório da oficina intitulada "A coincineração de resíduos em fornos de cimento: uma visão da Justiça Ambiental sobre o chamado coprocessamento", que foi realizada em 2006 no Rio de Janeiro, a prática do coprocessamento no Brasil pode gerar riscos à saúde dos trabalhadores e ao meio ambiente devido à formação e emissão de partículas poluentes, volatilização de metais pesados, bem como sua concentração e ainda o risco de acidentes durante o transporte dos resíduos da fonte geradora à indústria de cimento. Durante a Oficina, foram relatados casos com a finalidade de ilustrar a realidade do coprocessamento no Brasil.

Associando as ocorrências descritas, abordou-se a situação de risco dos trabalhadores da construção civil, que poderiam ser afetados 
pelas mudanças nas características do cimento produzido através do coprocessamento, uma vez que cimentos produzidos dessa maneira poderiam apresentar níveis mais altos de metais pesados.

\section{Produção técnico-científica sobre 0 coprocessamento}

Nos últimos 20 anos, ocorreu um aumento da produção científica em periódicos acerca do tema coprocessamento, conforme apresenta a Figura 1A, crescimento este acelerado a partir de 2002.

Foram publicados um maior número de artigos em periódicos do que em congressos, principalmente a partir de 2002, e o número de patentes se mostrou inferior ao número de artigos publicados (Figura 1B). O número de artigos em periódicos tem crescido mais nos últimos seis anos e o número de trabalhos apresentados e publicados em anais de congressos tem se mostrado aproximadamente constante, com algumas flutuações como uma redução no período de 1996 a 2002. O número de patentes foi maior no período de 1994 e 2006.

Os países que mais publicam em periódicos acerca do tema de coprocessamento são os Estados Unidos da América, o Reino Unido, o Brasil e o Canadá, respectivamente. O terceiro lugar ocupado pelo Brasil, com 15\% das publicações, atrás apenas do Reino Unido (17\%) e dos Estados Unidos (28\%), coloca o país a frente do Canadá (7\%) e de países como a Austrália, Bélgica, Holanda, Iugoslávia, Polônia,

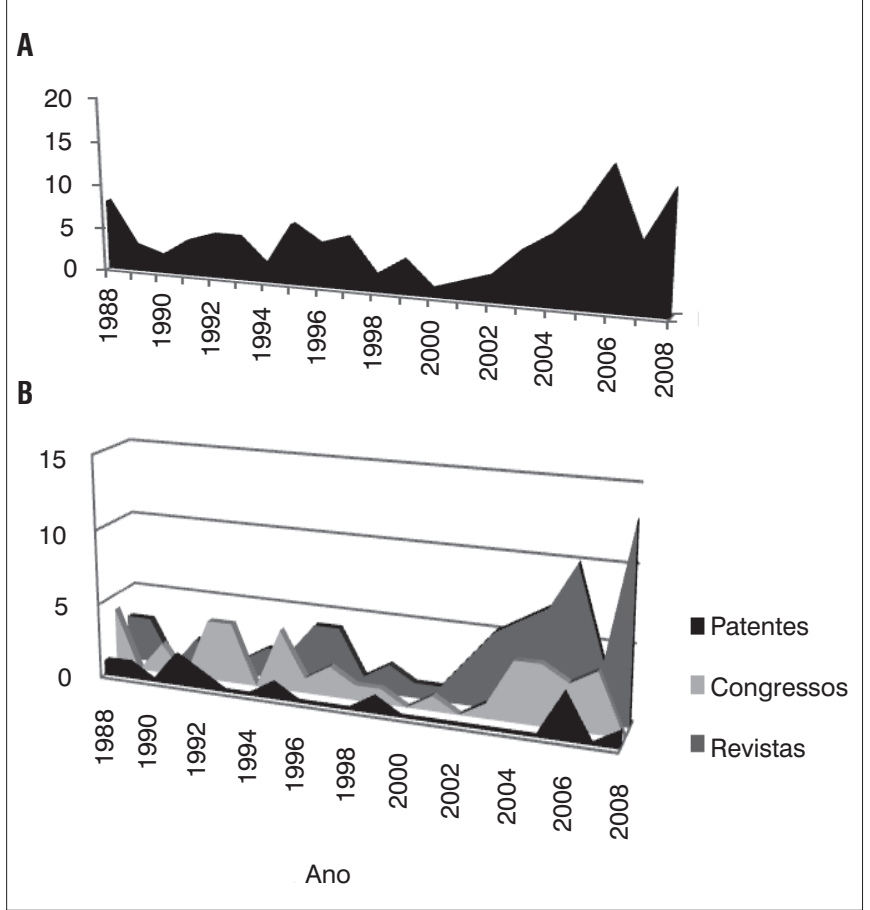

Figura 1 - (A) Número de publicações de artigos em periódicos sobre coprocessamento no período 1988-2008; (B) Número de patentes e artigos publicados em periódicos e em congressos.
Portugal, República Checa, Turquia e China, este país com apenas $2 \%$ das publicações. Os países menos cotados nessa classificação são a Estônia, a França, a Grécia, a Noruega, o Chile, a Índia e a Coreia do Sul. No Brasil, uma busca sobre os pesquisadores e grupos de pesquisa cadastrados no sistema Lattes do Conselho Nacional de Desenvolvimento Científico e Tecnológico (CNPq) mostrou que a produção bibliográfica sobre coprocessamento está diretamente relacionada com as regiões onde existem maiores concentrações de plantas cimenteiras do país.

Os centros de pesquisa do Estado de São Paulo produziram 37\% do total de trabalhos técnico-científicos sobre o coprocessamento no Brasil. Minas Gerais, Rio de Janeiro e Paraná figuram em segundo, terceiro e quarto lugar, respectivamente, produzindo 19, 15 e 13\% dos trabalhos técnico-científicos nacionais sobre o coprocessamento. Do total da produção científica levantada sobre o tema coprocessamento no país, 25\% são teses e dissertações, 19\% são artigos publicados em anais de congressos nacionais, 10\% são artigos publicados em congressos internacionais e 14\% são artigos em periódicos. Observase que as publicações científicas brasileiras vêm aumentando nos últimos 20 anos, e de forma mais acentuada a partir de 1994.

As publicações de 1988 e 1989 surgem quando são feitos os primeiros estudos sobre o coprocessamento para viabilizar respostas do setor para a crise desencadeada pela recessão da economia brasileira, nos finais da década de 1980. No início da década de 1990, quando se aplicou a tecnologia do coprocessamento em fornos de clínquer das cimenteiras de Cantagalo, foram publicados muitos trabalhos em resposta às denúncias sobre o desconhecimento de causa-efeito do coprocessamento na saúde dos operários dessas fábricas. Essas advertências dos jornais brasileiros e das agências de proteção ambiental surgiram em 1995-1996. A partir de 1998, houve um aumento das pesquisas sobre a segurança ambiental do coprocessamento e sobre novas tecnologias e novos materiais para o processo de coprocessamento. A perspectiva para os próximos anos é de que as pesquisas objetivem a otimização do processo e o desenvolvimento de tecnologias mais eficientes e seguras de coprocessamento de resíduos em fornos de clínquer.

Os temas abordados nas publicações nacionais e internacionais foram os aspectos ambientais (MILANEZ, 2007) e sociais (WINDER; CARMODY, 2002; WININGHAM, 1993) da atividade de coprocessamento, o emprego da ACV no estudo do coprocessamento e na quantificação dos impactos gerados por essa atividade (HUNTZINGER; EATMON, 2008; JOSA et al, 2007; NAVIA et al, 2006; LEE; PARK, 2004), e estudos do coprocessamento de resíduos específicos. Foi avaliado o emprego dos seguintes resíduos: combustíveis alternativos e híbridos da Europa Ocidental e Polônia (MOKRIZYCKI, 2003), lodos galvânicos (RACT; ESPINOSA; TENORIO et al, 2003), pesticidas e poluentes orgânicos (KARSTENSEN, 2006), resíduos da indústria siderúrgica (MALVIYA; CHAUDHARY, 2006; CAPONERO; TENÓRIO, 1999), resíduos derivados de combustíveis (GENON; 
BRIZIO, 2008), lama de esgoto proveniente do tratamento de água (ZABANIOTOU; THEOFILOU, 2008) resíduos cerâmicos (PUERTAS et al, 2008), e pneus inservíveis (MONTEIRO; MAINIER, 2008). Mirolli (2005) propôs um processo para produção de energia elétrica a partir do calor gerado pelos resíduos. Os aspectos mais relevantes a serem investigados no futuro são aspectos relacionados à eficiência energética, aos impactos ambientais e associados a resíduos específicos de maior interesse seja por questões de segurança, custo, ou quantidade do passivo ambiental. Cada resíduo deve ser investigado individualmente nos vários aspectos de seu coprocessamento: influência na qualidade do produto final, no consumo energético, nas emissões atmosféricas.

\section{Conclusão}

O coprocessamento de resíduos vem sendo cada vez mais utilizado, por razões ambientais e energéticas. Os resíduos utilizados como combustíveis alternativos reduzem o custo do processo, por substituir combustíveis convencionais requeridos pelas elevadas temperaturas do forno de clínquer. Com relação ao aspecto ambiental, o coprocessamento é uma alternativa de eliminação de resíduos que poderiam ter uma disposição de maior impacto ambiental. Os resíduos são processados nos fornos rotativos devido às condições específicas do processo como alta temperatura, ambiente alcalino, atmosfera oxidante, ótima mistura de gases e produtos, e tempo de residência geralmente suficiente para a destruição de resíduos perigosos. A adequabilidade do termo coprocessamento é questionada, mas é o mais utilizado na literatura, tanto no caso do uso de resíduos apenas como combustíveis, ou ainda como matéria-prima além de fonte de energia. A prática do coprocessamento de resíduos em fornos de cimento ainda demanda muitos estudos, visando-se elucidar os aspectos da real contribuição do coprocessamento de resíduos e o estabelecimento dos limites e riscos a ele associados, em processos onde um rígido controle das condições operacionais e um monitoramento contínuo e eficaz do processo e das características físicas e químicas dos resíduos não forem praticados.

\section{Agradecimentos}

Os autores agradecem ao Grupo Holcim pelo apoio ao trabalho.

\section{Referências}

ASSUNÇÃO, J.V.; PESQUERO, C.R. Dioxinas e furanos: origens e riscos. Revista de Saúde Pública, v.33, n.5, p. 523-530, 1999.

CAPONERO, J.; TENÓRIO, J.A.S. Caracterização do clínquer obtido no co-processamento de Lama de fosfatização. In: V Congresso Brasileiro de Cimento, Anais...Florianópolis: ABCP, 1999).

CARPIO, R.C. Otimização no Co-processamento de Resíduos na Indústria do Cimento Envolvendo Custos, Qualidade, e Impacto Ambiental. Itajubá, Tese (Doutorado em Engenharia Mecânica). Universidade Federal de Itajubá, 2005. 194 p.

Co-incineração de resíduos em fornos de cimento: uma visão da justiça ambiental sobre o chamado co-processamento. In: Oficina RBJA/FBOMS-CESTEH/ENSP/FIOCRUZ, Anais... Rio de Janeiro: RBJA/ FBOMS-CESTEH/ENSP/FIOCRUZ, 2006. p. 45

DICKSON, L.C; KARASEK, F.W. Mechanism of formation of polychlorinated dibenzo-p-dioxins produced on municipal incinerator fly ash from reactions of chlorinated phenols. Journal of Chromatography, v.389, p. 127-37, 1987.

GENON, G.; BRIZIO, E. Perspectives and limits for cement kilns as a destination for RDF. Waste Management, v.28, p. 2375-2385, 2008.

HUNTZINGER, D.N.; EATMON, T.D. A life-cycle assessment of Portland cement manufacturing: comparing the traditional process with alternative technologies. Journal of Cleaner Production, July, p. 1-8, 2008.
JOSA, A; AGUADO, A; CARDIM, A. et al. Comparative analysis of the life cycle impact assessment of available cement inventories in the EU. Cement and Concrete Research, v. 3, p. 781-788, 2007.

KARSTENSEN, K.H.; KINH, N.K.; THANG, L.B. et al. Environmentally sound destruction of obsolete pesticides in developing countries using cement kilns. Environmental Science \& Policy, v. 9, p. 577-586, 2006

HUNKELER, D.; LICHTENVORT, K.; REBITZER, G. Environmental Life Cycle Costing. Brussels: Society of Environmental, Toxicology, and Chemistry, p. 232, 2008.

LEE, K.M.; PARK, P.J. Estimation of the environmental credit for the recycling of granulated blast furnace slag on LCA. Resources, Conservation and Recycling, v. 44, p. 139-151, 2005.

LINS, V.F.C.; CASTRO, M.M.R.; LARA, A.A.; CURY, C.S.R. et al Seleção de resíduos sólidos para substituição da moinha de carvão em coprocessamento na indústria cimenteira. Relatório Técnico. Belo Horizonte. Universidade Federal de Minas Gerais, 2007.

MAINIER, F.B.; ROCHA, A.A. $\mathrm{H}_{2}$ S: Novas rotas de remoção química e recuperação de enxofre In: $2^{\circ}$ Congresso Brasileiro de $P \& D$ em Petróleo \& Gás, Anais...Rio de Janeiro: UFRJ, 1995. 6 p.

MOORE, T.E. Co-processamento de insumos alternativos In: Ciclo de Conferências: Indústria de cimento, fabricação, co-processamento e meio ambiente, Anais...: Rio de Janeiro: FEEMA, p.127-151, 1995. 
MALVIYA, R; CHAUDHARY, R. Leaching behavior and immobilization of heavy metals in solidified/stabilized products. Journal of Hazardous Materials, v. 137, n. 1, p. 207-217, 2006.

MILANEZ, B. Coincineração de resíduos industriais em fornos de cimento: problemas e desafios. In: $9^{\circ}$ Encontro Nacional sobre Gestão Empresarial e Meio Ambiente, Anais... Curitiba: ENGEMA, 2007.

MILLIGAN, M.S; ALTWICKER, E. The relationship between synthesis of polyclorinated dibenzo-p-dioxins and dibenzofurans and low-temperature carbon gasification in fly ash. Environmental Science Technology, v. 27, p. 1595-601, 1993.

MIROLLI, M.D. The kalina cycle for cement kiln waste heat recovery power plants. In: $44^{\text {th }}$ IEEE Conference on Decision and Control, Anais... Sevilha: IEEE, 2005.

MOKRIZYCKI, E.; ULIASZ-BOCHENCZYK, A. Alternative fuels for the cement industry, Applied Energy, v. 74, p. 95-100, 2003.

MONTEIRO, L.P.C.; MAINIER, F.B. Queima de pneus inservíveis em fornos de clínquer. Engevista, v. 10, n. 1, p. 52-58, 2008.

NAVIA, B.; RIVELA, B.; LORBER, K.E. et al. Recycling contaminated soil as alternative raw material in cement facilities: life cycle assessment. Resources Conservation and Recycling, v. 48, p. 339-356, 2006.

PORTO, M.F.S.; FERNANDES, L. O. Understanding risks in socially vulnerable contexts: The case of waste burning in cement kilns in Brazil. Safety Science, v. 44, p. 241-257, 2006.

PUERTAS, F.; GARCIA-DIAZ, I.; BARBA, A. et al. Ceramic wastes as alternative raw materials for Portland cement clinker production. Cement and Concrete Composites, v. 30, p. 798-805, 2008.

RACT, P.G.; ESPINOSA, D.C.R.; TENORIO, J.A.S. Determination of Cu and $\mathrm{Ni}$ incorporation ratios in Portland cement clinker. Waste Management, $\mathrm{v}$. 23, p. 281-285, 2003.
SANTI, A.M.M. Co-incineração e co-processamento de resíduos industriais perigosos em fornos de clínquer; investigação do maior pólo produtor de cimento do país. Região metropolitana de Belo Horizonte, MG. Tese, Campinas, 2003.

SANTI, M.M.; SEVÁ FILHO, A.O.S. Resíduos renováveis e perigosos como combustíveis industriais. Estudo sobre a difícil sustentação ambiental da fabricação de cimento no Brasil, anos 1990. In: VIII Congresso Brasileiro de Energia (CBE), Anais... Rio de Janeiro: CBE, 1999.

SIDHU, S.; KASTI, N.; EDWARDS, P. et al. Hazardous air pollutants formation from reactions of raw meal organics in cement kilns. Chemosphere, v. 42, p. 499-506, 2001.

SETAC. Society of Environmental Toxicology and Chemistry. In: Guidelines for Life-Cycle Assessment: A 'Code of Practice', Anais... Brussels: SETAC, 1993.

SWEETMAN, A; KEEN, C; HEALY, J; BALL, E, DAVY, C. Occupational exposure to dioxins at UK worksites. Annual Occupation Annual Occupational Hygiene, v. 48, n. 5, p. 425-437, 2004.

TOSTA, L.I.; SOUZA, A.C.; SILVA, R.J. Gestão da energia na produção de cimento portland com uso de mineralizadores e combustíveis alternativos. In: $27^{\circ}$ Encontro Nacional de Engenharia de Produção (ENEGEP), Anais... Foz do Iguaçu: ABEP, p. 10, 2007.

WINDER, C.; CARMODY, M. The dermal toxicity of cement. Toxicology and industrial health, v. 18, n. 7, p. 321-31, 2002.

WININGHAM, W. Safeguards for burning waste-derived fuel in cement kilns. In: IEEE Cement Industry Technical Conference, Toronto: IEEE. p. 183-200, 1993.

ZABANIOTOU, A.; THEOFILOU, C. Green energy at cement kiln in Cyprus - Use of sewage sludge as a conventional fuel substitute. Renewable and Sustainable Energy Reviews, v. 12, p. 531-541, 2008. 